This item was submitted to Loughborough's Research Repository by the author.

Items in Figshare are protected by copyright, with all rights reserved, unless otherwise indicated.

\title{
Eligibility and bad news delivery: How call-takers reject applicants to university
}

PLEASE CITE THE PUBLISHED VERSION

https://doi.org/10.1016/j.linged.2018.07.001

PUBLISHER

(C) Elsevier

VERSION

AM (Accepted Manuscript)

PUBLISHER STATEMENT

This paper was accepted for publication in the journal Linguistics and Education and the definitive published version is available at https://doi.org/10.1016/j.linged.2018.07.001.

LICENCE

CC BY-NC-ND 4.0

\section{REPOSITORY RECORD}

Hoey, Elliott M., and Elizabeth Stokoe. 2018. "Eligibility and Bad News Delivery: How Call-takers Reject Applicants to University". figshare. https://hdl.handle.net/2134/34124. 
Eligibility and bad news delivery:

How call-takers reject applicants to university

Elliott M. Hoey, University of Basel, Switzerland

Elizabeth Stokoe, Loughborough University m UK

Published in Linguistics and Education, accepted $4^{\text {th }}$ July 2018 https://doi.org/10.1016/j.linged.2018.07.001 


\title{
Eligibility and bad news delivery: \\ How call-takers reject applicants to university
}

\begin{abstract}
This paper examines how delivering bad news may be avoided in conversations where rejection is common. We collected 2000 recordings of telephone calls from prospective students to a UK university contact centre during an annual process called 'Clearing and Adjustment'. Applicants call to secure a place on a degree programme but are often ineligible due to insufficient grades. Based on a sample of 200 calls analysed using conversation analysis, we show that call-takers determined applicants' eligibility in two main ways: call-takers could 1) solicit applicants' grades, or 2) inform applicants about the course's entry requirements. Following solicitations, call-takers' next action was to reject applicants. However, following informings, students deduced their own ineligibility and explicit rejection was avoided. The relationship between method ('solicit' v. 'informing') and the occurrence of overt rejection was highly significant ( $\mathrm{p}<0001)$. We discuss the implementation of our findings in call-taker training to enable them to avoid giving out rejections.
\end{abstract}

Keywords: Conversation Analysis, preference organization, rejection, university admissions, eligibility, bad news 


\section{INTRODUCTION}

In this paper, we focus on a signal moment in the lives of many young people in the UK: a telephone call whose outcome determines whether and where they will be able to go to university. These are 'clearing and adjustment' calls, where prospective undergraduate students call universities with the aim of securing a place on a degree programme that may have places available. The majority of applicants are unsuccessful in securing a spot, which means that the call-takers representing the university are often tasked with the delicate business of rejecting applicants. Our interest is in how such rejections are organized, and in particular, the sequential trajectories of two actions - informings and solicitations - that routinely lead to rejections. Both of these actions are recurrently used by call-takers when determining the eligibility of an applicant. However, we show that they are not equivalent in their affordances. With solicitations, the call-taker ends up knowing everything needed to render a decision, whereas with informings, it is the applicant who retains that information. Our findings have implications for training calltakers to inform callers of course requirements, rather than ask what grades callers achieved, because doing so systematically provides for the avoidance of giving or receiving an explicit rejection. In other words, it prevents call-takers from having to deliver bad news, and callers having to receive it.

\subsection{Preference organization and institutional settings}

Rejection is tricky, not only for the one being rejected but also for the one doing the rejecting. Research on social interaction has described rejections in terms of a 'preference organization', with rejections being regularly treated by participants as dispreferred actions (Pillet-Shore, 2017). Preference organization refers to how particular sequential environments structurally favour certain actions or outcomes over their alternatives, typically in service of promoting prosociality and minimizing conflict (Heritage, 1984; Schegloff, 2007). Many dispreferred actions, such as rejections, refusals, and disagreement, are discordant with the desires and wants of others and therefore may undermine solidarity (Clayman, 2002). Actions like these typically exhibit features that index their dispreferred status vis-à-vis actions that are structurally favoured or preferred. Whereas preferred actions like acceptance, agreement, and granting are often promptly produced and straightforwardly designed, dispreferred actions are routinely delayed, 
accompanied by accounts, and relatively elaborate in their design (Pomerantz, 1984; Sacks, 1987). Parents' rejections of their children's requests, for instance, often feature mitigation of the rejection, less-than-full granting, and avoidance of outright refusals like no (Wootton, 1981).

In this article, we focus on dispreferred actions in an institutional setting. Practices geared toward the organization of preference are often similar in institutional settings like courtrooms (Atkinson \& Drew, 1979) and scientific laboratories (Lynch, 1985), but can differ in crucial respects. For example, whereas disagreements in ordinary conversation tend to be delayed and mitigated, disagreements in news interviews are rarely accompanied by these features (Greatbatch, 1992). The modulation of preference organizational features in different institutional contexts is bound up with the particulars of those settings and the types of activities that occur there. Take requests, for instance. An important feature of requests in institutional settings is the client's entitlement to make a request in the first place (Curl \& Drew, 2008). Clients may feel relatively more entitled in some situations, like requesting an appointment when calling one's doctor (Sikveland, Stokoe, \& Symonds, 2016), or requesting to book a flight when calling an airline service (Lee, 2011). When the client is normatively entitled to service, the rejection or non-granting of a request is often accompanied by accounts, apologies, and offers of alternative solutions (Varcasia, 2007). Conversely, in other situations, client entitlement may be moderated due to contingencies like availability and feasibility of service, legitimacy of the request, and client eligibility for service. Problems may arise when callers and call-takers are misaligned regarding what is due to whom under what conditions (Tracy, 1997). For example, call-takers at emergency and police services may decide that the caller's issue does not merit dispatching their limited resources (M. Whalen \& Zimmerman, 1990; J. Whalen \& Zimmerman, 1998).

\subsection{Clearing and adjustment calls}

This article builds on prior work on the sequential organization of rejections in institutional interactions by focusing on a particular context: telephone calls made to a UK university call centre during the clearing and adjustment stage of the undergraduate admissions process. At this stage, there are a number of vacancies in various courses of study for the upcoming year, and a surplus of applicants for these vacancies. The process of clearing and adjustment is addressed to 
the organizational problem of distributing a limited resource - offers of admission — to qualified applicants (see the Appendix for greater detail about how students arrive at this stage).

The most basic concern in clearing and adjustment calls is determining the applicant's eligibility for an offer. Each course requires that applicants have particular grades on their 'Alevel exams' (or simply 'A-levels'). Some have the grades to qualify, but of course not all do. If an applicant's grades render them ineligible for a particular course, they may enquire after another course at that same university, or they may call other universities to see if they qualify for courses there. Applicants are therefore under pressure to locate a course that accepts their grades. In addition to the matter of eligibility, timing is another practical pressure. The telephone lines for clearing and adjustment all open on the same day at the same time, and when they do universities are inundated with calls. There is a collective scramble to call because offers are given to eligible applicants on a first-come-first-served basis. So even if an applicant's grades are good enough to qualify for a particular course, that course may already be at capacity. Clearing and adjustment calls are thus a rushed competition for a limited resource. Applicants are interested in receiving an offer on their desired course at their desired university - getting the best they can with what they've got. And similarly, universities are interested in filling their courses with the most qualified students; if those students commit to enrolling elsewhere, universities may be left with empty seats and less qualified students.

These calls are a kind of gatekeeping interaction (e.g., Erickson, 1975; cf. He, 1998) and as such offer a lens onto the processes that constitute society's educational institutions (see Schegloff, 2006). They show how participants manage access to prized goods (university admission) and navigate categorical shifts in identity (from university applicant to university student). The importance of analyzing such issues is reflected in the worldwide growth in demand for tertiary education. From 2000 to 2014 alone, the number of students in higher education institutions more than doubled, rising from 100 million to 207 million (Global Education Monitoring Report, 2017). The massive industries and organizations implicated in this rapid growth deserve greater scrutiny from social scientists and education researchers. This article contributes to this goal by describing in fine detail the interactional mechanisms whereby applicants to university are determined to be eligible for admission and how participants manage the rejections that are inevitably part of that process. 


\subsection{Eligibility and rejection in clearing and adjustment calls}

An example of a typical clearing call appears below. ${ }^{1}$ The caller (A, for "Applicant") tells the call-taker (U, for "University representative") that he's hoping to apply tuh computer science (lines 4-5).

1. $\mathrm{CC}-36$

$01 \mathrm{U}$ : Morning=Leffingwell university

02 contact centre.=how can I help?

03 A: Hello, my name's: u:h Muhammet

04 Vekilov? I'm hoping to apply tuh

05 computer science through: clearing?

$06 \mathrm{U}$ : All right? (.) give me a second?

$07 \quad(0.2)$

$08 \mathrm{~A}$ : No problem.

$09 \quad(3.3)$

$10 \mathrm{U}: \mathrm{A}: \mathrm{nd}$ what are your $\overline{\mathrm{A}}$ level grades?

$11 \quad(0.7)$

12 A: U:h a Bee, a Cee, an' a Dee. in: computing:,

13 maths, a:nd physics.

$14 \quad(1.6)$

$15 \mathrm{U}$ : Unfortunately, the minimum requirementi

16 for our computer science courses

17 through clearing, is $\overline{\mathrm{A}} \overline{\mathrm{A}} \overline{\mathrm{A}}$ ?

18 A: O:kay,

$19 \quad(1.4)$

$20 \mathrm{U}: \mathrm{C}^{\prime} \mathrm{I}$ help you $\mathrm{w}^{\prime}$ anythin' else?

$21 \quad(0.3)$

22 A: . MK=u:h no, that's okay.=thank you very

23 much.

$24 \mathrm{U}$ : All right then, have a n[ice day.

25 A : [buh-bye.

Having been apprised of the student's course of interest (computer science), the representative proceeds to locate it on his computer while the applicant waits (lines 6-9). Locating the course

${ }^{1}$ Transcripts follow Jeffersonian conventions (see Hepburn \& Bolden, 2017). 
allows him to check the course's availability (open to all, not open, only open to international students, etc.) and its entry requirements (typically three letter grades like AAA, ABB, etc.). ${ }^{2}$ After locating the course information, the representative solicits the applicant's A-level grades (line 10). He begins his question with a turn-initial and, which situates his question as part of the larger course of action (Heritage \& Sorjonen, 1994) of determining the applicant's eligibility. The applicant then produces his three A-level grades and specifies which subjects they were in (lines 12-13).

The representative now knows the two pieces of information required to render a decision: the grade requirements (which he checked on the computer) and the applicant's A-level grades (which he solicited). The representative prefaces his decision with unfortunately, which forecasts something contrary to a hoped-for outcome, then tells the applicant what grades are required for computer science (lines 15-17). By pointing out the grade requirements (AAA), the representative invokes the discrepancy between them and the applicant's grades (BCD), thereby producing what amounts to a rejection. The applicant receipts this with $o$ :kay (line 18), which displays acceptance of the prior action and its implications (Beach, 1993). After a brief lapse in their talk (line 19) during which neither participant self-selects (Hoey, 2015), the representative moves to close their conversation (line 20; Schegloff \& Sacks, 1973; Hoey, in press).

This extract shows the basic features of clearing/adjustment calls. The applicant indicates interest in a particular course or courses, and then the participants proceed to determine eligibility. This involves a comparison of grades required and grades received. In this case, the representative is the one who is able to make such a comparison, and who lets the applicant know that their grades will not earn them a place on their course of interest.

This extract also shows how the representatives in these calls treat rejections as dispreferred. ${ }^{3}$ The representative's rejection turn (lines 15-16) is relatively elaborate rather than short and direct; he prefaces it with unfortunately, orienting to the news as distressing for the caller; the rejection itself is formulated as an informing rather than an explicit rejection like we cannot accept you; and the actual rejection component (i.e., the statement of $A A A$ ) does not occur until the end of his turn. Additionally, a 1.4s lapse emerges in the place where he could have

\footnotetext{
${ }^{2}$ If the applicant has done an "International Baccalaureate", they do not have three letter, but a score up to 45 points. ${ }^{3}$ Applicants also treat rejections as dispreferred in this setting, though not as systematically as the representatives. We return to this asymmetry in the discussion.
} 
elaborated on his informing (line 19). But instead, after the lapse the representative directs the conversation to other matters (line 20). That is, more explicit rejections appear to be avoided or displaced.

These telephone calls thus offer a perspicuous setting for analyzing the management of rejections. Structurally, clearing and adjustment calls are distinct from institutional interactions where callers may be entitled to receiving some service (e.g., Lee, 2011). Here, an applicant has no assurance of receiving an offer. Even if an applicant holds excellent grades or enquires about dozens of courses, those courses may be full or only open to particular kinds of applicants. This rationing of offers is reflected in our dataset, where only $17 \%$ of calls $(34 / 200)$ resulted in the applicant receiving an offer.

Our interest in the organization of rejections in institutional settings emerges from a basic concern with how call-takers deliver a lot of bad news. Put simply, how do they spend all day giving out rejections to hopeful university applicants? As previously noted, people ordinarily make some effort to mitigate, delay, or otherwise obscure a rejection. In this paper, we examine how this works in a high-rejection setting. While our analysis pertains directly to the materials analyzed below, our findings have more general relevance for understanding institutional interaction; that is, what are the procedures by which institutional participants check for eligibility for service (e.g., Sikveland, et al., 2016)? We describe two generic practices whereby the university representative determines an applicant's eligibility and compare these two practices with respect to the actual production of rejections. We will show that one practice (solicitation) systematically provides for the production of rejections in this setting whereas another practice (informing) does not.

\subsection{Data and methods}

Our data are 2266 audio recordings of telephone calls made to the clearing and adjustment call centre of a UK university in the summer of 2016. These were made available by the university for the purpose of identifying practices which could be used for training purposes (more on this in section 3.5). We selected a random sample of 200 calls to analyze for this article. The caller was usually the university applicant but was sometimes a teacher or family member calling on the applicant's behalf. And the call-taker was one of several university representatives trained to take clearing and adjustment calls. As is standardly the case in call-centres, callers were 
informed that their calls were being recorded for research and training purposes. Data were stored securely under encryption and all extracts were anonymized. The language of these calls was almost entirely British English. The analysis proceeds according to Conversation Analytic methods and principles. Conversation Analysis (CA) is an inductive and predominantly qualitative micro-analytic method for uncovering the tacit, taken-for-granted practices with which participants organize their everyday circumstances (see Sidnell \& Stivers, 2013; Hoey \& Kendrick, 2018).

Our basic aim was to determine how participants organized the critical portion of the calls where it became known whether the applicant would get an offer or not. In what follows, we first show that there are two major ways for determining the eligibility of the applicant for a given course (3.1). We then detail the sequential trajectories of these two methods, first describing solicitation sequences (3.2) and then informing sequences (3.3). Next, these methods are then compared in terms of which one results in more rejections (3.4). We situate this analysis in the context of the training recommendations which we delivered to the university that supplied the data (3.5).

\subsection{Results}

\subsection{Two main methods for determining eligibility}

The two critical pieces of information for clearing/adjustment calls are the grades required to get on the course and the grades the student received. Participants can handle this information in several ways (cf. Heritage, 2012). The applicant, for example, can supply their grades without being prompted to do so, like in Extract 2, or they can ask what the grade requirements are, like in Extract 3.

\section{2. $\mathrm{CC}-016$}

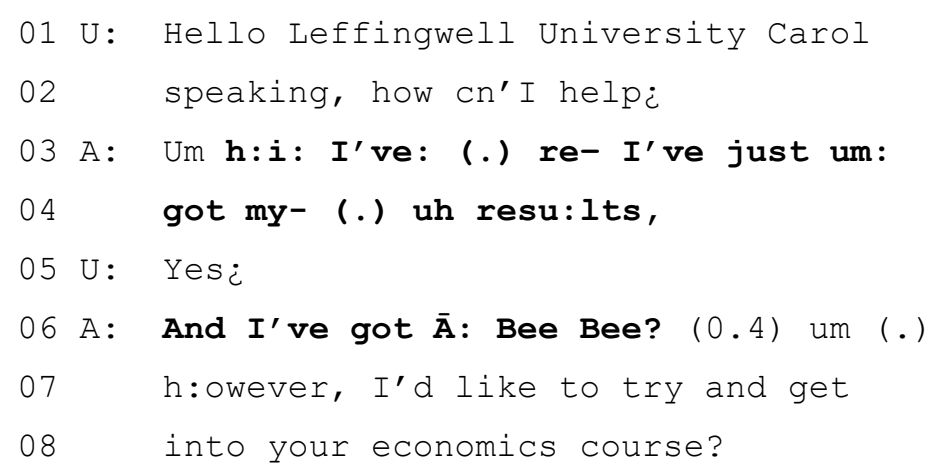


$09 \mathrm{U}: \quad(\mathrm{m}) \mathrm{ka}: \mathrm{y}$.

$10 \quad(0.5)$

$11 \mathrm{U}$ : Let me have a quick look at

12 what vacancies we've go: $t_{i}$

\section{3. $\mathrm{CC}-038$}

$01 \mathrm{U}:$ We've got: s:paces in mathematics with

02 (.) economics?

03 A: Ye[ah?

$04 \mathrm{U}: \quad$ [That's th- (.) bachelors? (0.3)

05 a: [nd then um there' $\mathrm{s}=$

06 A: $\quad$ [yes.

$07 \mathrm{U}:=\mathrm{m}$ : athematics with economics $\uparrow$ with a

08 placement year,

09 A: Okay? . h=u[m

$10 \mathrm{U}: \quad\left[\mathrm{w}^{-} \mathrm{w}^{-}\right.$(.) yeah?

$11 \mathrm{~A}$ : Yep can I have the $\uparrow$ grade boundaries

12 for them, please,

$13 \mathrm{U}$ : Ye:ah um, mathematics with economics

14 requires a minimum of $<\overline{\mathrm{A}} \overline{\mathrm{A}}$ Bee $>$ ?

University representatives also use different ways to solicit this information. They may ask about the applicant's grades, as in Extract 1, or they may ask if the applicant wants to know the grade requirements (Extract 4) or inform them of those grades outright (Extract 5).

\section{CC-070}

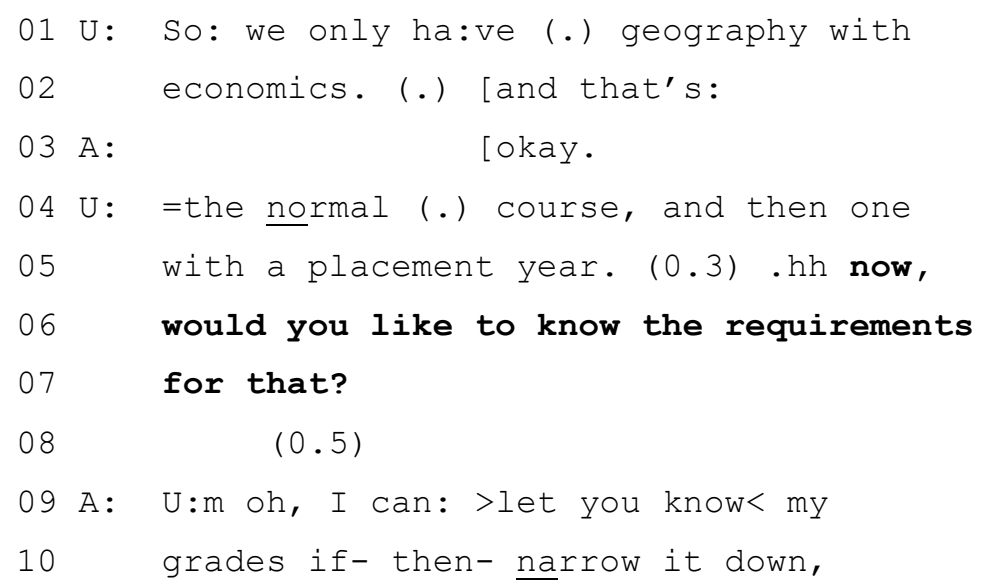


5. $\mathrm{CC}-010$

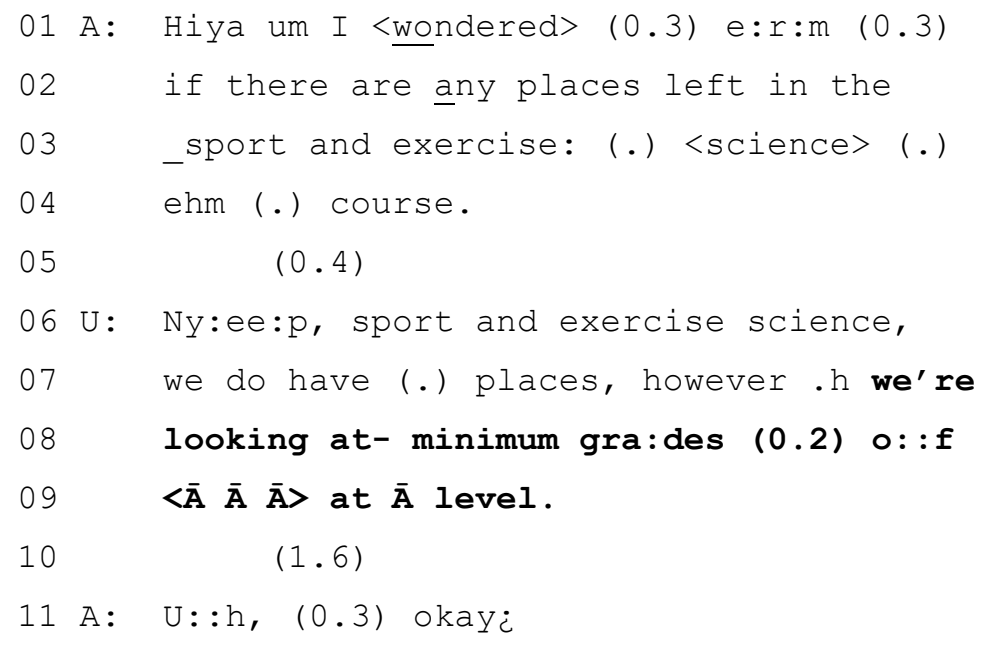

Table 1 below shows the distribution of these methods across a sample of 200 calls. Cases were categorized as "Other" if there were fewer than five cases of the phenomenon in the collection (e.g., the caller both discloses their grades and asks what the requirements are).

\begin{tabular}{|l|c|c|}
\hline How grades are handled & $\boldsymbol{N}$ & Proportion \\
\hline Representative solicits applicant's grades & 88 & $44 \%$ \\
\hline Representative informs of grade requirements & 38 & $19 \%$ \\
\hline Course not available or grades not relevant & 30 & $15 \%$ \\
\hline Caller supplies applicant's grades & 21 & $10.5 \%$ \\
\hline Other & 13 & $6.5 \%$ \\
\hline No resolution to call & 5 & $2.5 \%$ \\
\hline Reason for call is another matter & 5 & $2.5 \%$ \\
\hline Total & 200 & $100 \%$ \\
\hline
\end{tabular}

Table 1: Distribution of ways that grades are handled

As Table 1 shows, solicitations and informings together comprised the most common methods for handling grades, accounting for 63\% (126/200) of calls. The remainder of the calls were 23 cases $(11.5 \%)$ where the student's course of interest was not available, meaning the matter of grades was not relevant; 21 cases $(10.5 \%)$ where the caller supplied the student's grades, and 30 
cases $(15 \%)$ of a diverse set of situations, each relatively small in number (for example, Extracts 4 and 5 were categorized as 'Other').

This distribution indicates that there are two basic ways that participants determine whether the applicant is eligible for a place on a particular course: The representative either (1) solicits the applicant's grades, or (2) informs them of the grade requirements for the course. We describe these options in more detail in the following two sections.

\subsection{Solicitation sequences}

The most common way that participants handled the matter of eligibility was through solicitation sequences. Such sequences typically had three parts: 1) the representative solicits the applicant's grades; 2) the caller provides the grades; and 3) the representative delivers a decision about the applicant's eligibility. The first of these actions - the solicitation turn - ordinarily featured a straightforward question, as shown above in Extract 1 (line 10) and in the extract below (line 1).

\section{CC-180}

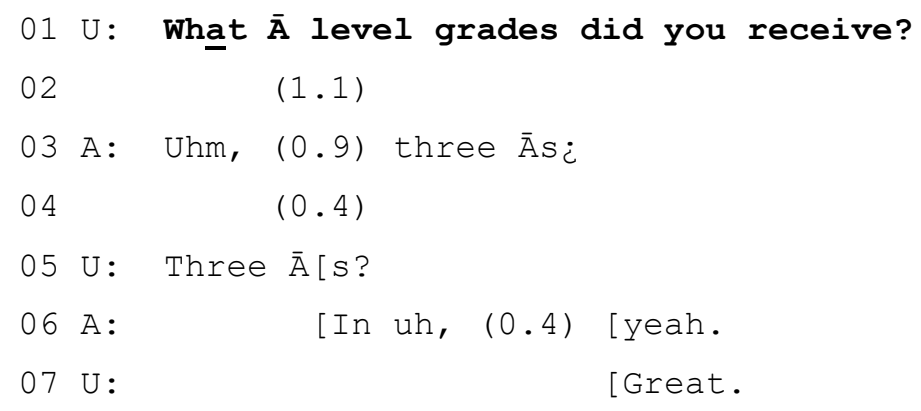

Solicitations also appeared with permission-seeking prefaces like $c n$ I just ask (Extract 7, line 1). Phrases like this revealed an orientation to the applicant's negative face, or desire to be unimpeded in one's actions (Brown \& Levinson, 1987). They cast the request as minimally imposing and formally provided for the option to decline the request.

7. CC-116

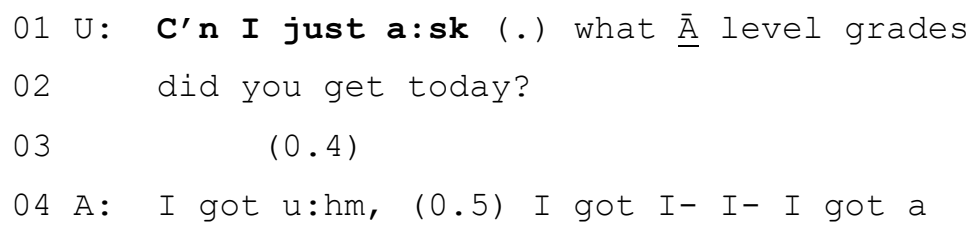


In some cases, solicitations occurred after a 'pre-sequence' (Schegloff, 2007; cf. Fox, 2015; Rossi, 2014), like in Extract 8. That is, the call-taker first establishes that the applicant has Alevel grades, then once the applicant confirms that she does, the call-taker solicits them with a question.

8. CC-004

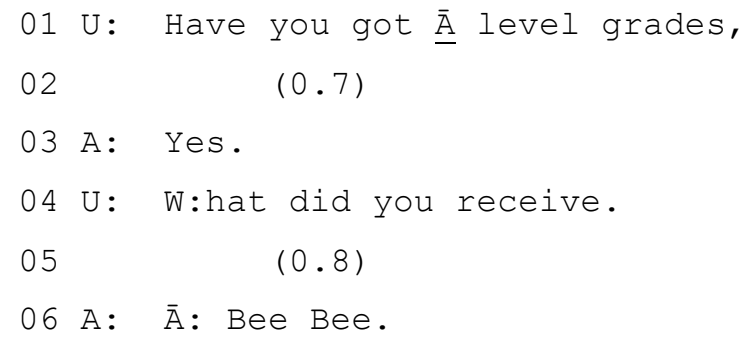

In response to solicitations, applicants ordinarily gave their A-level grades. At its most basic, this consisted of three letter grades (e.g., Extract 8), but often included the specific courses that those grades were for as well (e.g., Extract 1).

In the third action of the solicitation sequence, we see what representatives did after being given the applicant's grades. There are two relevant actions in this sequential position. If the applicant's grades met or exceeded the grade requirements, then the representative could proceed with the application process. But if they were below what was required, then the representative was faced with rejecting the applicant. There were relatively few cases $(n=23)$ where the applicant's grades met or exceeded the requirements. One such case appears below.

9. CC-180

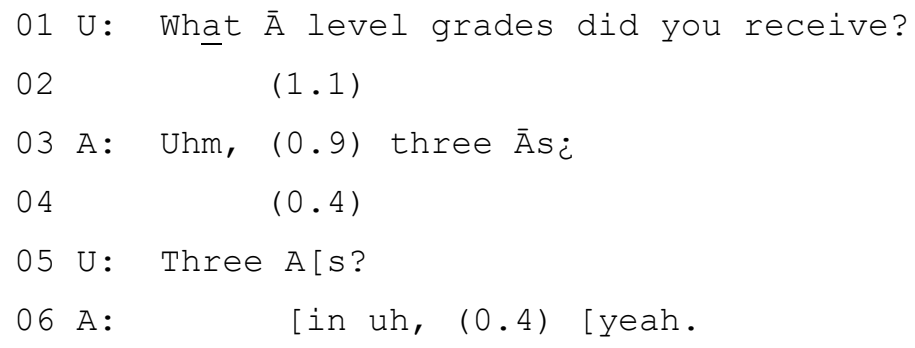




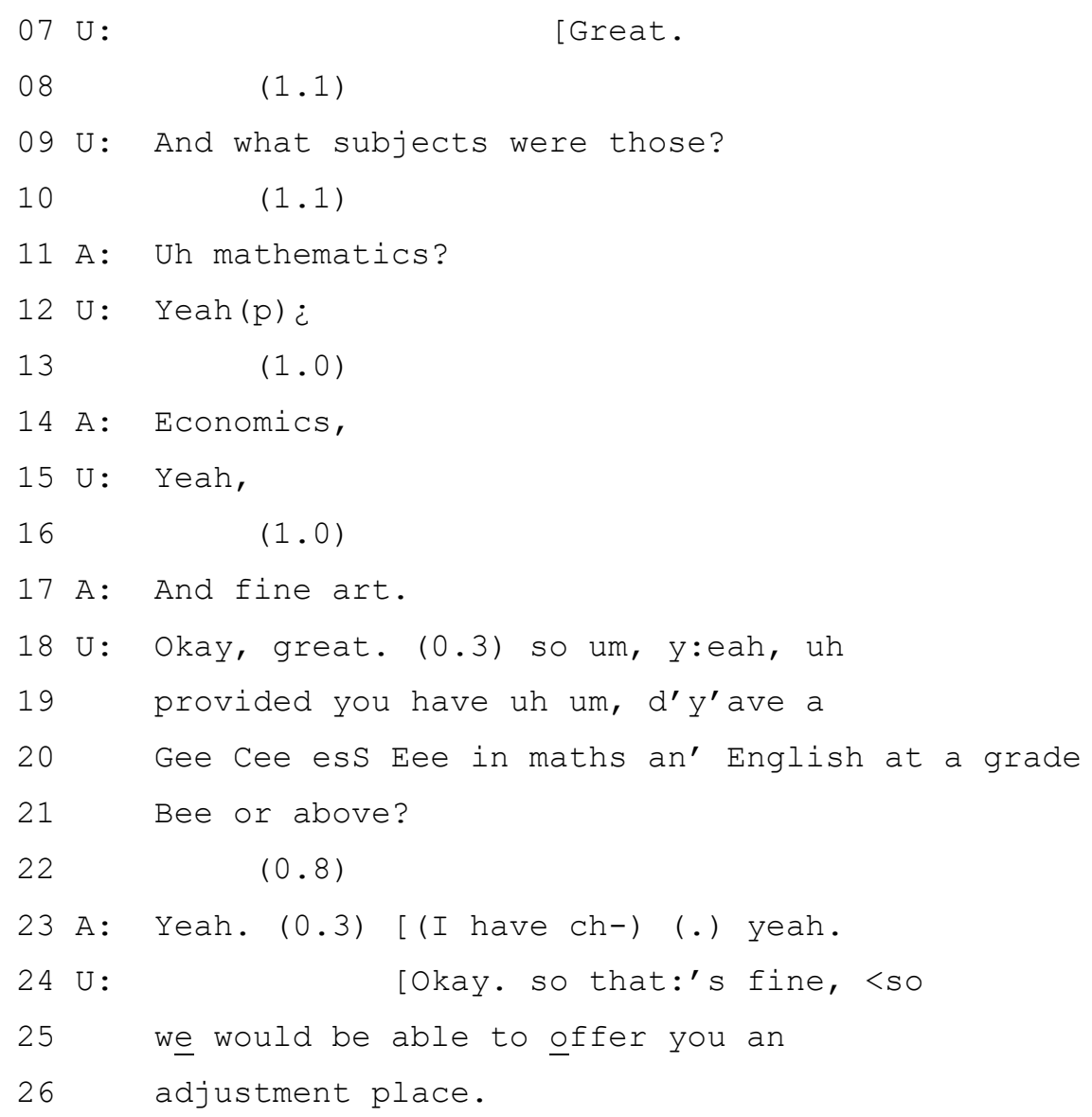

After the caller's grades were solicited and provided (lines 1-7), the representative simply proceeds with more questions about the applicant's academic achievements (lines 9-21). By advancing with more questions about the student's academic background, the representative treats the applicant as eligible-thus-far.

For most solicitation sequences, however, the applicant's grades were too low to qualify them for an offer $(n=62)$, which made rejection the relevant next action. These rejections were formatted in several ways. Some were relatively direct, in the sense that the connection between the applicant and the non-provision of an offer was made clear. Direct rejections often included some formulation of failure or inadequacy on the part of the student. In Extract 10, the representative formulates her rejection by reference to the applicant's failure (lines 17-19).

10. CC-165

$01 \mathrm{U}:$ Can you confirm your results for me 02 please? 


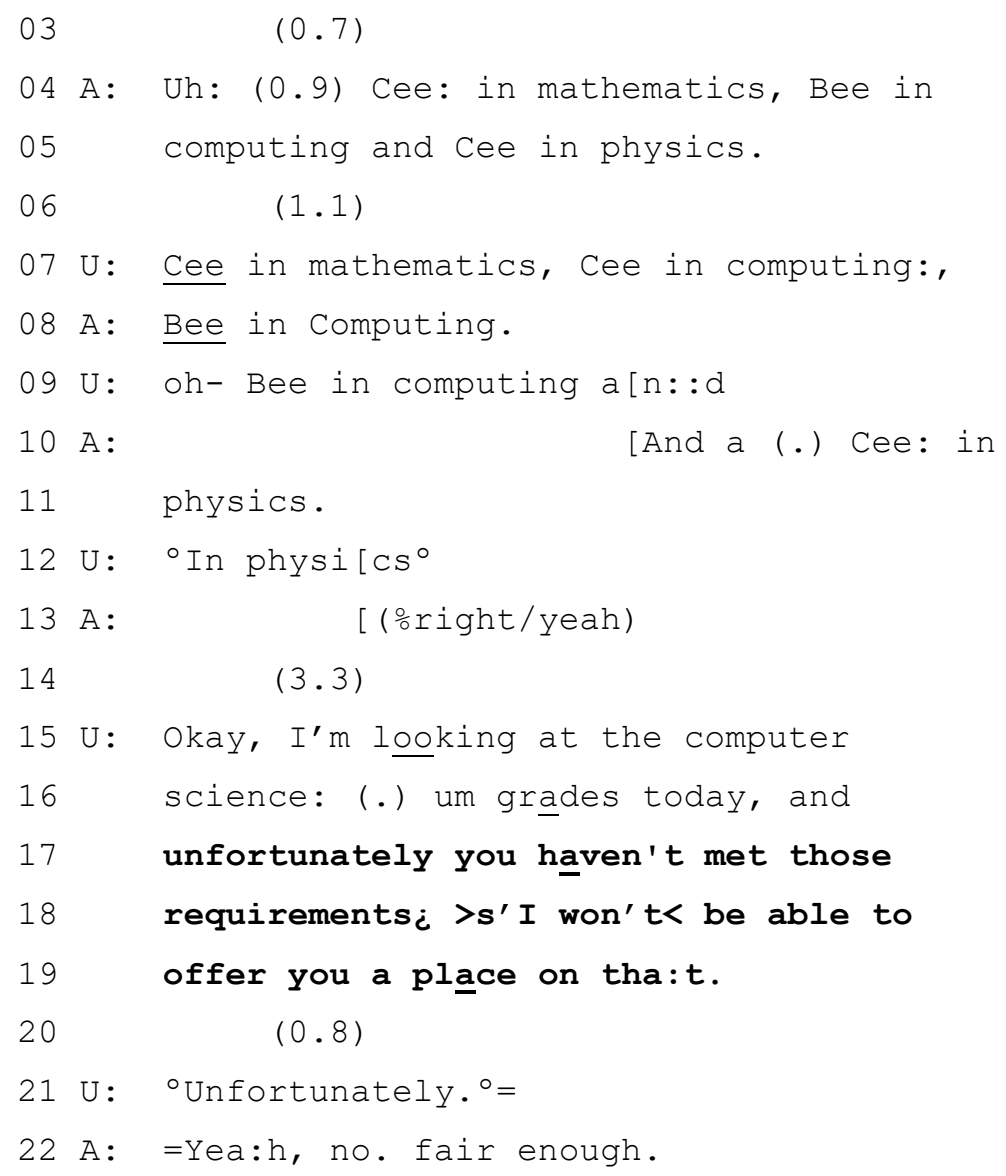

She tells the applicant you haven't met those requirements, followed by a logical outgrowth of that failure, so I won't be able to offer you a place. This locates the source of the rejection as firmly in the domain of the applicant. Note also that the bad news is prefaced (and forecast) by the word unfortunately (line 17), which is repeated (line 21) after a gap develops (line 20) once the news is out.

Direct rejections also included unambiguous statements about acceptance to the university and use of the second person pronoun you. In Extract 11, after the applicant's grades are solicited and supplied (lines 1-2), the representative baldly states that we wouldn't be able to accept you onto psychology, and directly references those grades that the applicant had received.

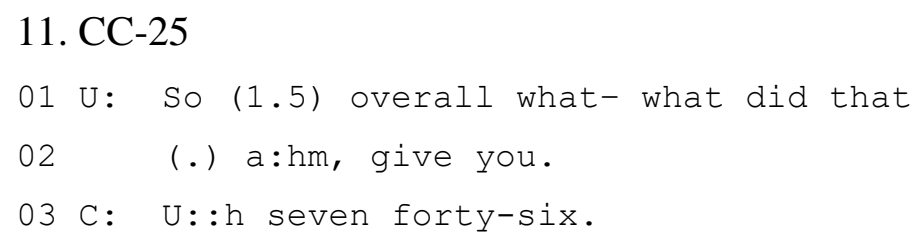




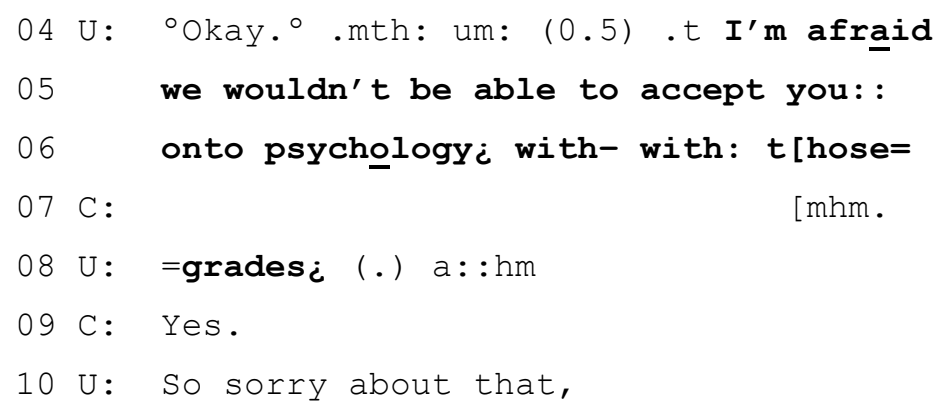

In other cases, rejections were more indirect and did not explicitly reference what will happen or what motivates the decision. Often, this took the form of stating the minimum grade requirements to get onto a course. In Extract 12, like Extract 11, the call-taker prefaces and forecasts the upcoming bad news with I'm afraid (line 8; Maynard, 1997) then specifies that three As are required for the course. Also like Extract 11, the call-taker follows up the bad news with a comment that displays their understanding that the caller will treat the news as such (So sorry about that, line 10). Extract 12 is similar.

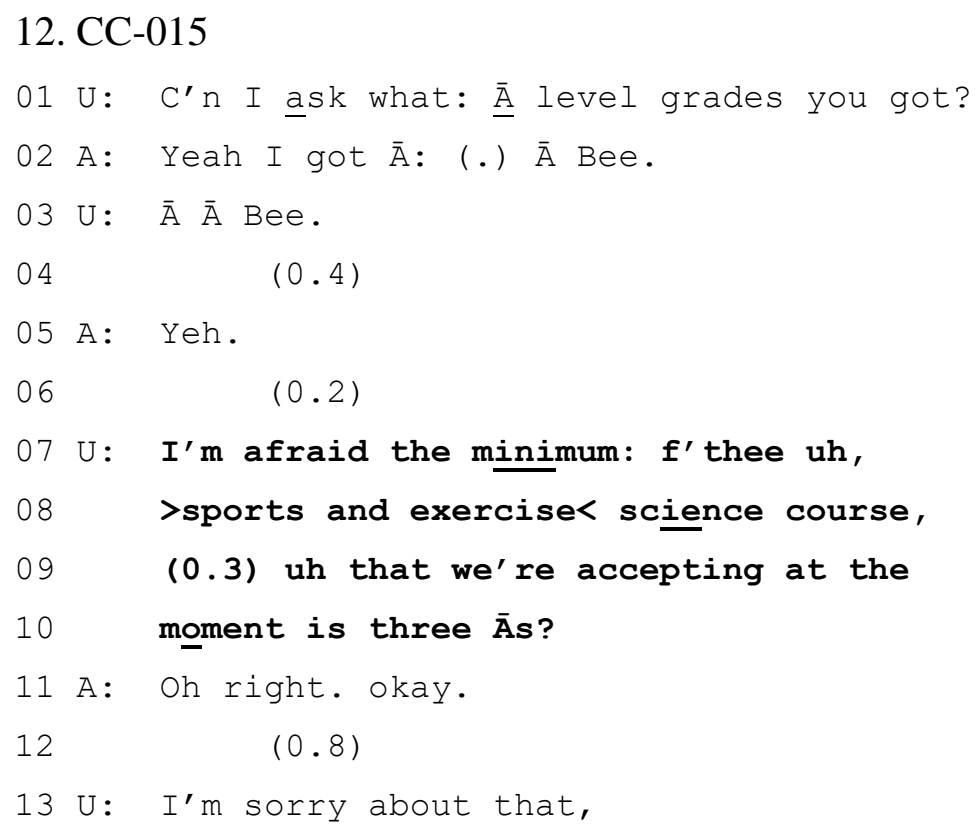

By revealing the grade requirements, the representative invokes the discrepancy between the grades required and the grades received. The applicant receipts this statement as a rejection. He acknowledges what it implies with oh right. okay. (line 11; Beach, 1993; Schegloff, 2007). Nowhere in this rejection is there an explicit formulation of whether or not that particular 
applicant would be accepted. Rather, the applicant is left to deduce that no offer is forthcoming (see Gill \& Maynard, 1995; Maynard, 2004).

Indirect rejections were also done by reference to course availability, as Extract 13 shows, below. After the applicant reveals his grades (line 2), the representative begins her response by projecting bad news with I'm afraid. She indicates not having any courses for him with those entry requirements at the moment (lines 5-7).

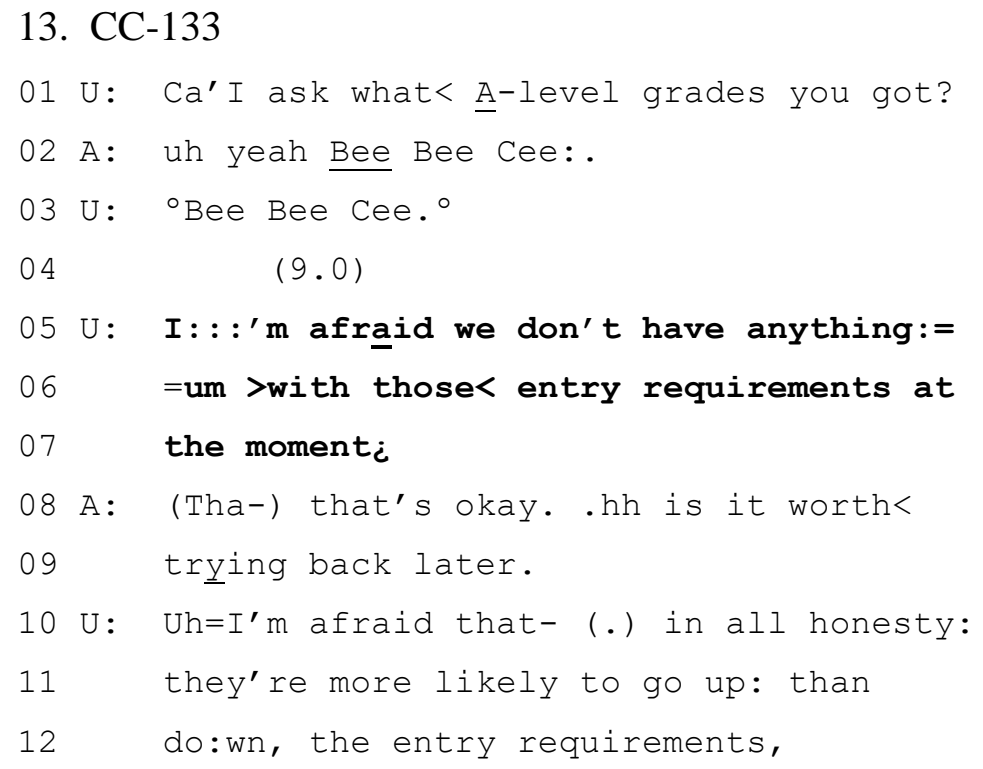

The rejection in this case is a result of university's inventory, not the student's inadequacy. It is framed as a matter of what the university can do with what they have on hand, and so puts some distance between the rejection and the student.

Some non-grantings (Lee, 2011) were framed such that neither the university nor the student was directly implicated in the decision. In Extract 14, after the applicant provides their grades, the representative responds by referencing the number of times they have raised their grade boundaries that day and the volume of calls (lines 9-14).

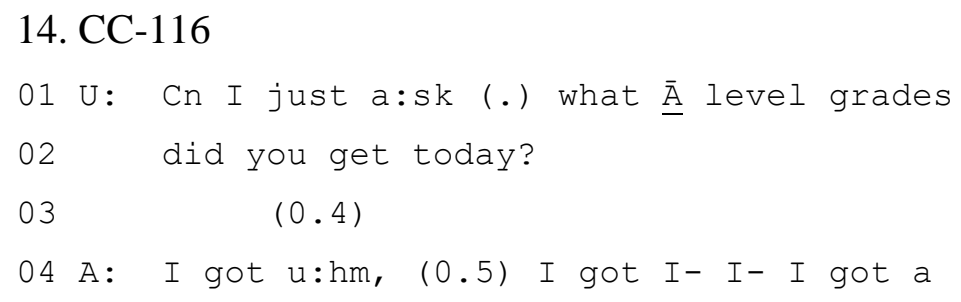




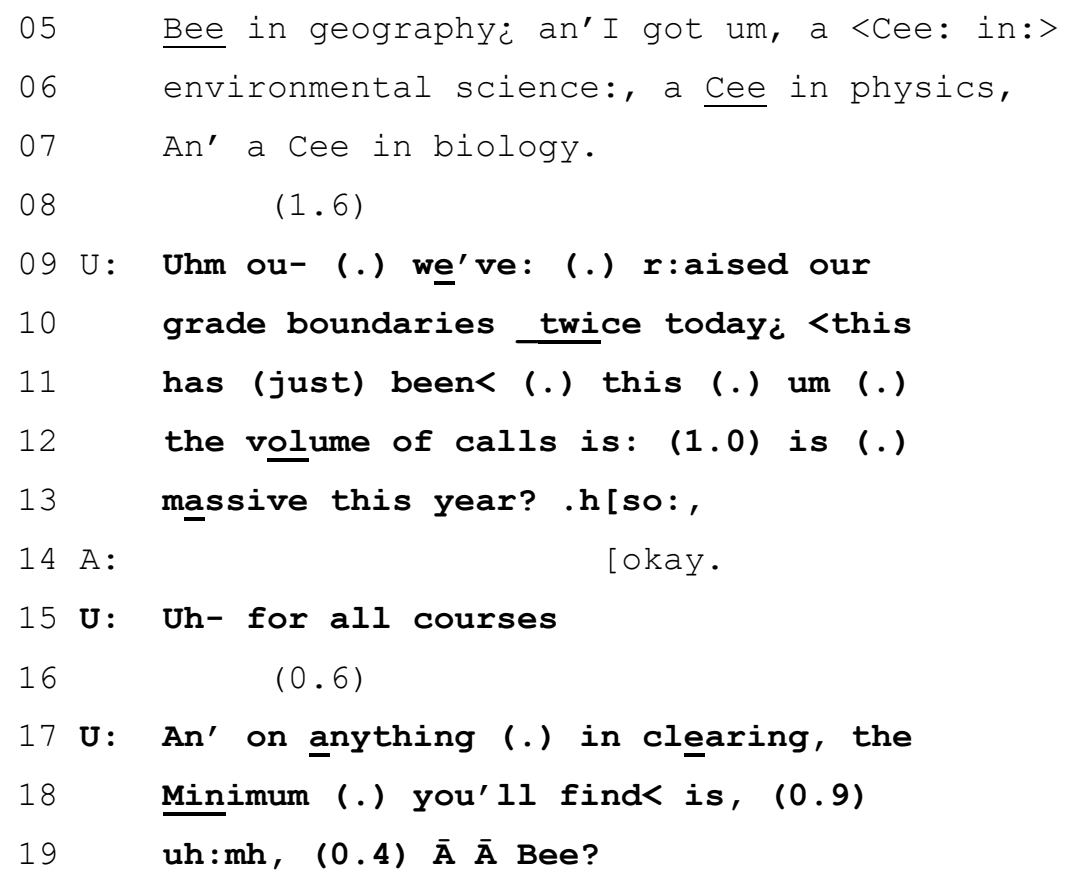

In her description of the day's events so far, the call-taker emphasizes the word twice and describes the volume of calls as massive. These details work to render the circumstances as out of the ordinary and therefore as an account for what she says next. Using turn-initial so (line 13), she connects these circumstances to an upshot about the minimum grades for courses in clearing, similarly emphasizing the totality of their reach (for all courses, on anything in clearing, the Minimum you'll find). By accounting for the rejection using the extraordinariness of the situation, the representative implies that the applicant may have been accepted under ordinary circumstances. In this way, it is neither the university nor the applicant who is responsible for the rejection, but the number of calls they have received, which is not something that any individual can control and is not, therefore, a personal rejection

With solicitations, the university representative elicits a critical piece of information-the student's grades — and uses that to come to a decision about the applicant's eligibility. In solicitation sequences, the representative is systematically afforded the opportunity to do something with the information provided (cf. Sacks, 1992, 'Lecture 7 On questions'). This sequential trajectory contrasts with informing sequences, described in the following section.

\subsection{Informing sequences}


The other major way of determining the applicant's eligibility was through informings, where the call-taker states grade requirements for the applicant's course of interest. The fundamental component of an informing was a specification of the letter grades. The most basic form this took was a statement of the three grades, as below (lines 5-7).

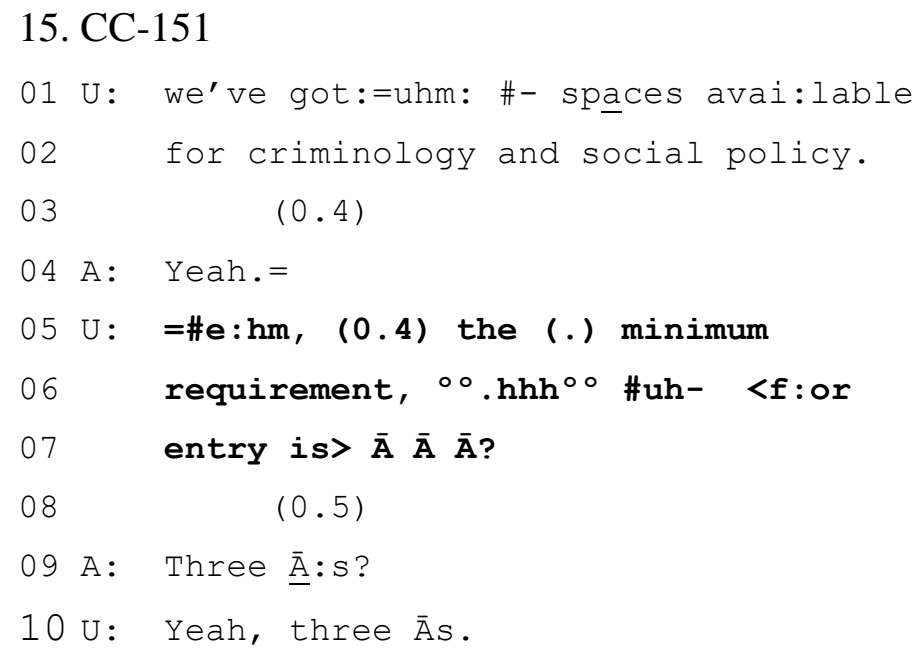

In addition to the three letter grades, representatives could also specify what courses those grades need to be in. In CC-104, the representative indicates that AAB is required with a Bee in geography.

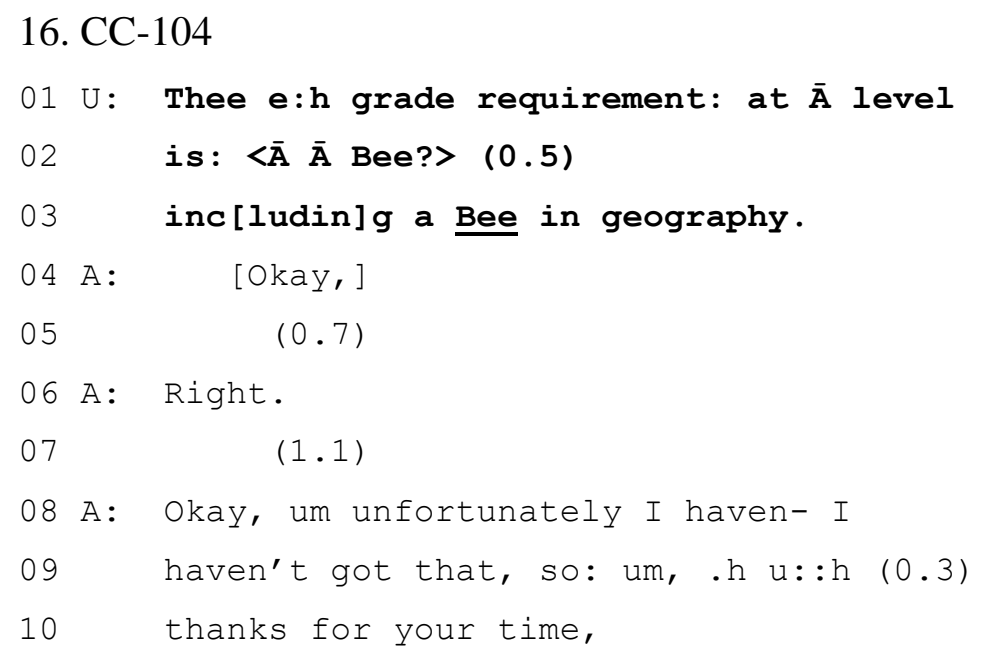

Representatives could also qualify their informings with adverbial clauses like according to the website (Extract 17) and at the minute (Extract 18). Note in Extract 17 that, while the call-taker 
refers to the website as supplying information about eligibility, the applicant refers to your clearing in response, showing the back and forth management of accountability and agency in (non)grantings.

\section{CC-45}

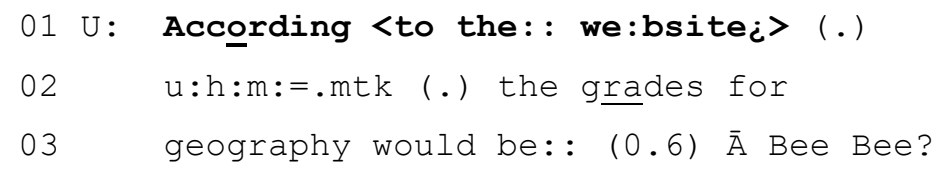

18. CC-182a

$01 \mathrm{U}:$ Yeah, so >at the minute< $\overline{\mathrm{A}}$ level

02 grades are $<\overline{\mathrm{A}}$ Bee Bee? $>$ with an $\overline{\mathrm{A}}$

03 level: grade Bee in English?

These qualifications orient to particular contingencies related to the clearing and adjustment process. Most saliently, grade requirements may change over the course of the day. As applicants receive offers, there become fewer and fewer seats to fill, and if these applicants are all high quality students (i.e., all have high A-level grades), then the grade requirements increase as well. And so with qualifications like at the minute and according to the website, representatives orient to the dynamic nature of the grades.

After the informing, applicants are in a position to do something with that information. They possess both pieces of information needed to assess their eligibility - the grades required and the grades received. And so in informing sequences, applicants are systematically afforded the opportunity to direct the application process. This contrasts with the sequential trajectory of solicitation sequences, where the representative possessed the critical information and was therefore in a position to guide the call at that moment. In responses to informings, we observe a greater range of actions. If the applicant's grades met/exceeded the requirements, they simply proceeded with the application process, as below.

\section{CC-087b}

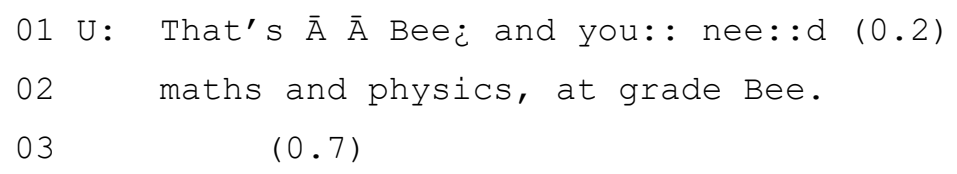




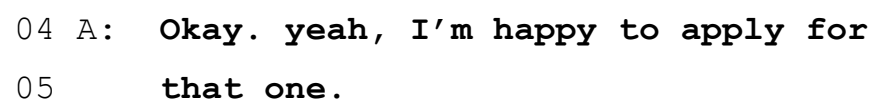

After the representative informs the applicant of the requirements, the applicant acknowledges (okay) and treats the informing as if it were an offer (yeah, I'm happy to apply for that one). The applicant uses the informing to transition to the next phase of the interaction, where they officially advance with the application.

Extracts where applicants met the grade requirements were relatively rare, however $(n=$ 6). It was more common that the applicant's grades were insufficient to merit admission $(n=32)$. In these cases, the applicant faced the problem of what to do with the implication of no offer. We observed two main types of responses: applicants could resist $(n=9)$ or accept the implication of no offer $(n=19)$.

\section{Resistance}

Applicants may resist, challenge, or otherwise not go along with the implication of no offer. For instance, an applicant may react with surprise to the informing (Wilkinson \& Kitzinger, 2006) and go on to challenge its validity, as in Extract 20 below. After being told that the minimum requirement for entry is AAA, the applicant repeats three A's? (line 4).

20. CC-151

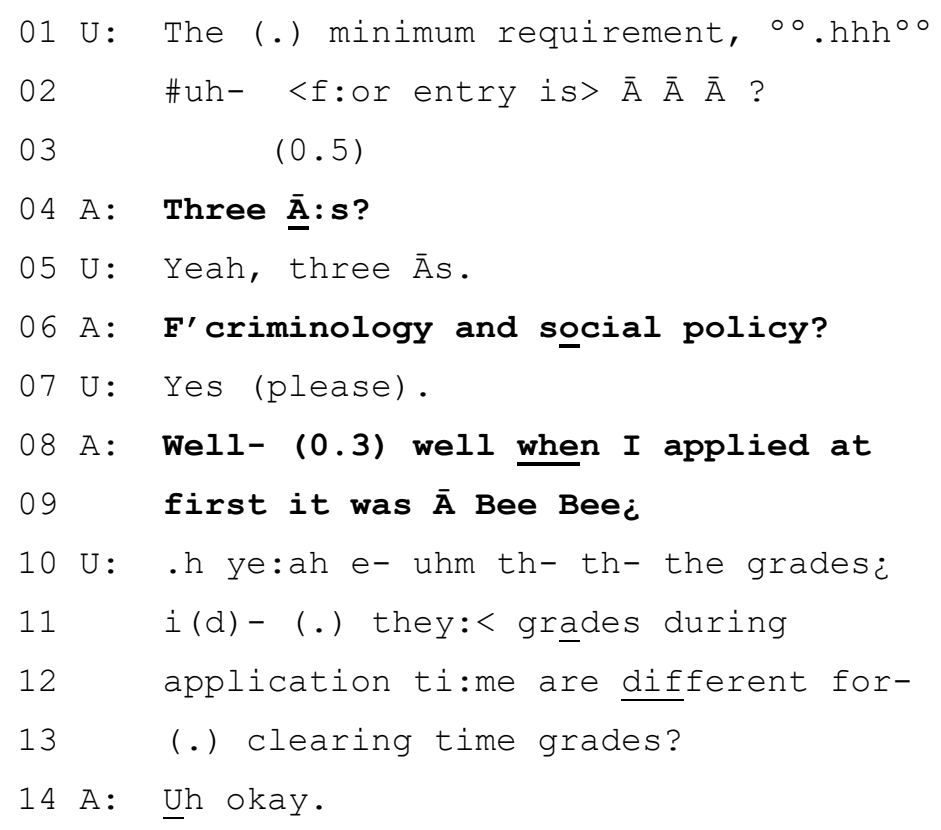




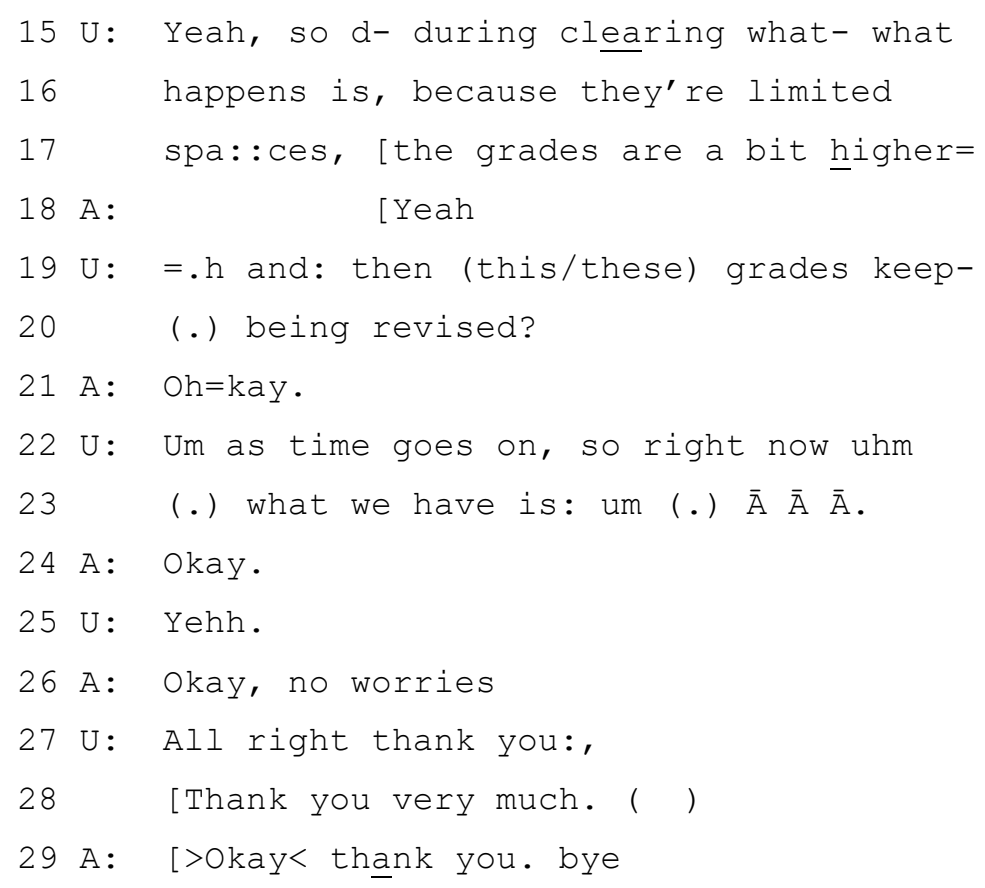

The applicant's repetition initiates a further repair sequence in which the representative confirms that yeah, three As are needed (lines 4-5). The applicant evidently remains incredulous, as he challenges another component of the talk (f'criminology and social policy?), which the representative again confirms (lines 6-7). Gaining no purchase with his repair initiations, the applicant switches strategies. He starts a well-prefaced turn, which projects a 'my side' perspective (Heritage, 2015), and cites the reason for his protest: the divergence between grade requirements when he applied at first and the requirements now at clearing (lines 8-9). This somewhat antagonistic stance on the part of the caller makes relevant from the representative some justification or account. As we see, the representative goes on to explain why the grades requirements are now higher (lines 10-23). This explanation amounts to a rejection, and the applicant treats it as such by moving to end the call (lines 24-28). So by challenging the informing, the applicant created a place where it was relevant for the representative to more resolutely produce a rejection.

A somewhat less disaffiliative way that applicants resist the implication of an informing is by disclosing the grades they have received. Below, the applicant is informed that he needs at least an AAB in particular courses (lines 1-5).

21. CC-39 


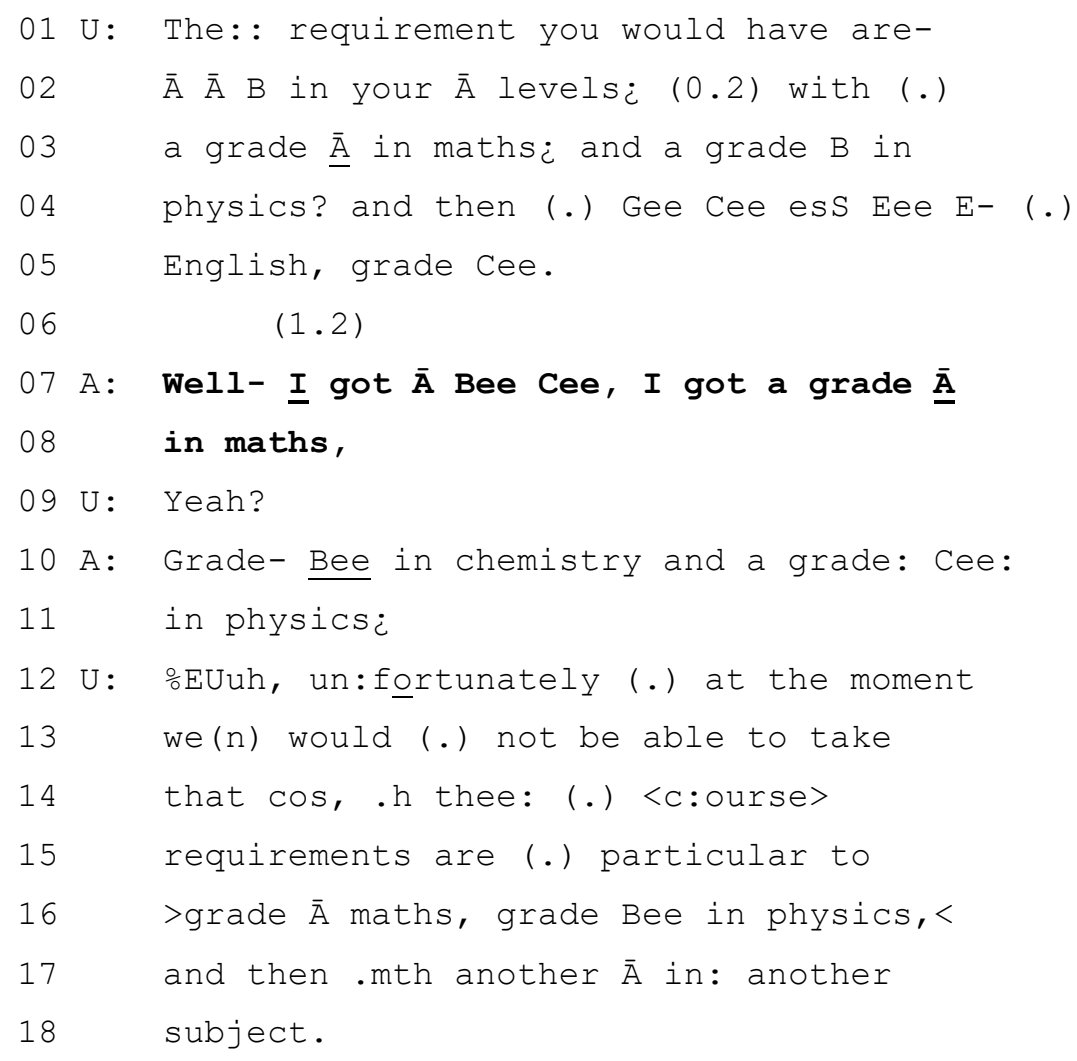

The applicant treats the informing as an occasion to share his grades. He projects giving his own perspective with turn-initiall well (Heritage, 2015), then proceeds to disclose his grades, which are patently lower than what's required. With this, the applicant neither accepts the implication of no-offer nor denies the discrepancy between the grades required and grades received. Rather, his grade disclosure is hearable as a kind of pleading, as if to ask 'can you do anything with these grades?'. It arms the representative with the information to render a decision and creates a sequential slot where such a decision may be placed. In response to the applicant's disclosure, the representative gives a direct rejection (we would not be able to take that) and justifies it by more explicitly laying out the conditions of acceptance (lines 12-18).

\section{Accept implication of no offer}

Applicants may accept the implication of no offer and move on to something else. This acceptance can be an open admission of having inadequate grades, as in Extract 22. Here, the applicant is informed that $\mathrm{AAB}$ is required for the geography course. He receipts the informing first with okay (line 6), then after some silence, re-acknowledges it with right (line 8). Having 
been informed of the requirements, the applicant is in a position to evaluate whether his grades qualify him for the course.

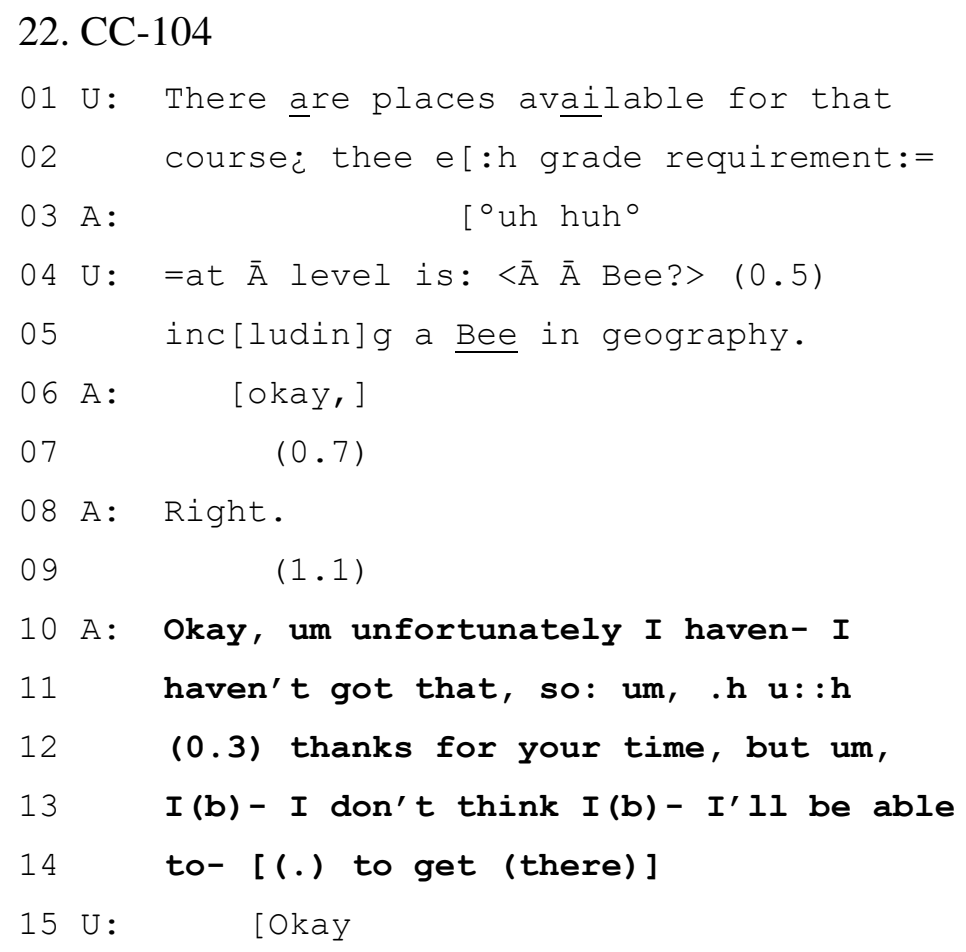

After a momentary lapse, the applicant again acknowledges the informing with okay, then launches into his response. He gestures to an unfavourable state of affairs with unfortunately, then confesses to not having the grades required (line 10). His turn-continuation (so: um) projects some consequence of his confession. However, in the place where that consequence might be articulated, there is a bit of disfluency and silence, after which the applicant moves to end the call (lines 12-14). And so with the grade requirements in hand, the applicant discerns that he's ineligible for the course and takes himself out of the running.

The last example showed how applicants may openly admit to having inadequate grades. However, they need not confess to this failure. Instead, they may simply move on to something else. In Extract 23, after being informed of the grades needed for the $M$ Eng (master's in engineering), the applicant acknowledges that information with okay, then proceeds to ask about another course, the B Eng (bachelor's in engineering).

\section{CC-087a}




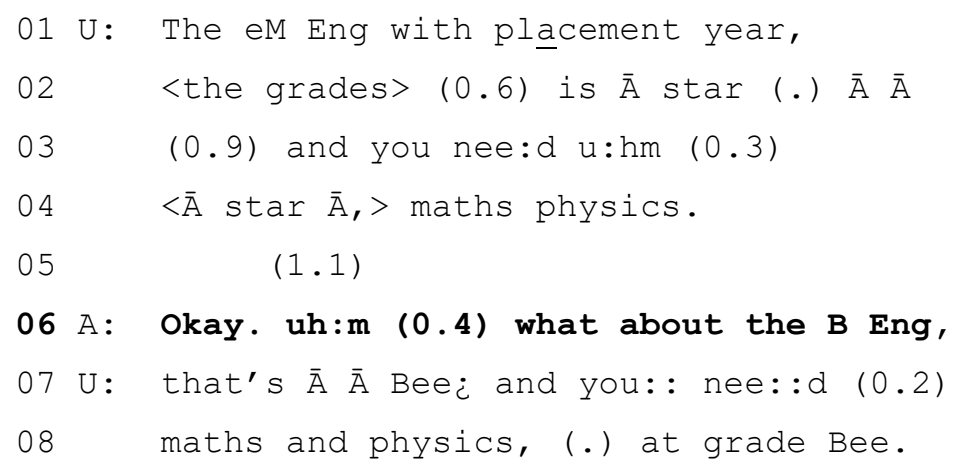

This inquiry guides the call toward consideration of another course. By inquiring after other possibilities in this sequential environment, the applicant bypasses the matter of his grades, which aren't given at all, and only implicitly indicates their insufficiency. Similarly, in the next extract there is no confession of having inadequate grades. Instead, the applicant cuts the application process short.

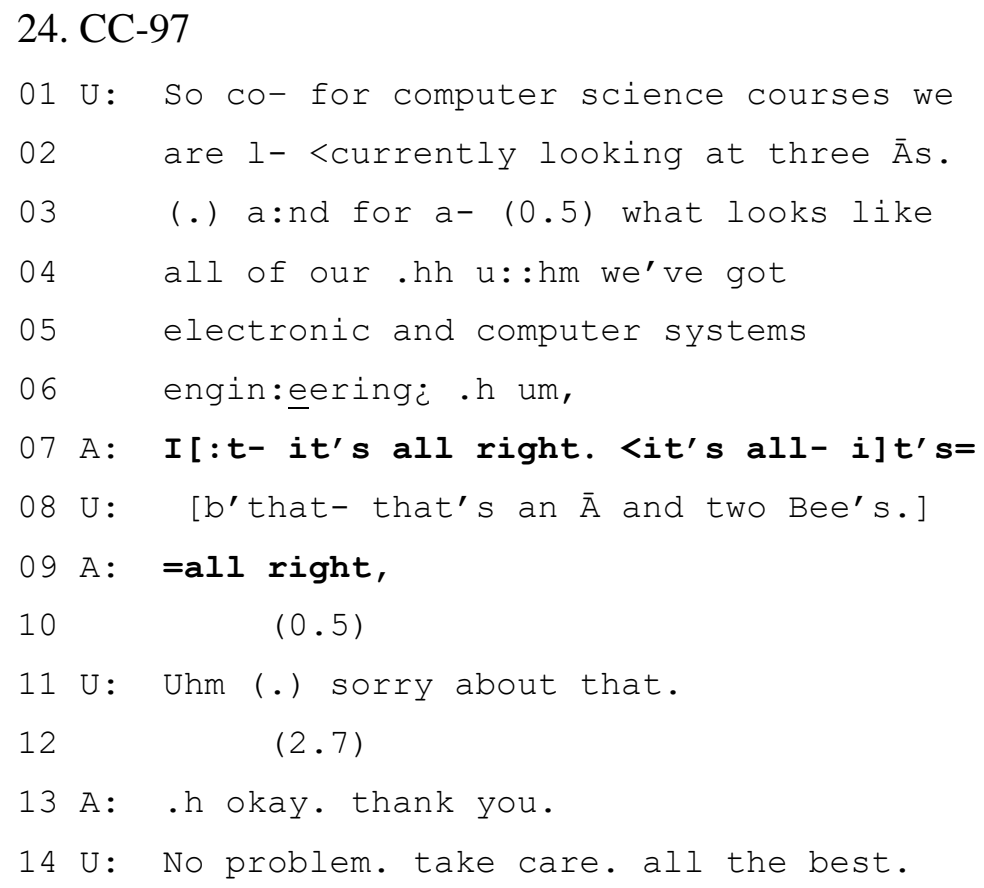

The applicant gives an it's all right multiple saying, which curtails the course of action underway and treat its continuation as unnecessary (Stivers, 2004). For the applicant, talk about the application process has at this point already gone on too long. The representative then issues an apology, acknowledging the unfavourable state of affairs for the applicant and perhaps also 
apologizing for having needlessly gone on. With the application process foreshortened, the participants may move onto something else. It is not obvious which participant is responsible for guiding the call at this point, and so neither elects to speak, giving rise to a 2.7-sec lapse. Finally, the applicant ends the lapse by moving to end the call (line 13; Schegloff \& Sacks, 1973).

These extracts show that informing sequences are a systematic alternative to solicitation sequences, and that they provide for the circumvention of overt rejection. Applicants are able to bow out of the application process gracefully without explicitly divulging their grades, and then either move onto some other matter or propose ending the call. This preserves an applicant's positive face (i.e., the desire to be liked and seen as competent; Brown \& Levinson, 1987) by removing the sequential relevance of a rejection. No slot is provided where rejection is relevant, and so participants do not have to give or receive a rejection.

\subsection{Solicitation sequences structurally provide for rejections}

The previous section described the two main methods for determining the applicant's eligibility: solicitation sequences and informing sequences. In terms of informational exchange (e.g., Heritage, 2012), these options are roughly equivalent. One party - the applicant or the representative - comes to know all the information required to determine whether the applicant can proceed. We might conclude that it does not really matter which is selected, as the 'same' result would come out either way (the applicant does or does not get an offer). However, as we have seen, solicitation sequences unfold quite differently than informing sequences. In particular, we argued that solicitation sequences systematically produce rejections, while informing sequences allow participants to avoid giving/receiving rejections. When we look at our collection as a whole, we see that this sequential pattern also bears out distributionally.

In solicitation sequences, rejections (both direct and indirect) are common after the applicant reveals the grades they'd received. If we simply look at whether or not a solicitation sequence contains a rejection, then we see that rejections occur in $70.5 \%$ of the data (Table 2).

\begin{tabular}{|l|l|c|c|c|c|}
\hline Response type & \multicolumn{2}{|c|}{$N$} & \multicolumn{2}{c|}{ Proportion } \\
\hline Rejection & \multicolumn{2}{|c|}{62} & \multicolumn{2}{|c|}{$70.5 \%$} \\
\hline \multirow{2}{*}{ Something other than rejection } & Call-taker proceeds & 23 & \multirow{2}{*}{26} & $26.1 \%$ & \multirow{2}{*}{$29.5 \%$} \\
\cline { 2 - 3 } & Other & 3 & & $3.4 \%$ & \\
\hline
\end{tabular}




\begin{tabular}{|l|c|c|}
\hline Total & 88 & $100 \%$ \\
\hline
\end{tabular}

Table 2: Frequency of rejections and non-rejections in solicitation sequences

We can similarly inspect informing sequences for any instance of a rejection or rejection. We see that rejections occur in only $18.4 \%(n=7)$ of informing sequences, whereas actions other than rejection are more common, accounting for $81.6 \%(n=31)$ of the data.

\begin{tabular}{|c|c|c|c|c|c|}
\hline \multicolumn{2}{|l|}{ Response type } & \multicolumn{2}{|c|}{$N$} & \multicolumn{2}{|c|}{ Proportion } \\
\hline \multirow{4}{*}{$\begin{array}{l}\text { Something other } \\
\text { than rejection }\end{array}$} & After applicant accepts no-offer implication & 18 & \multirow{4}{*}{31} & $47.4 \%$ & \multirow{4}{*}{$81.6 \%$} \\
\hline & After applicant resists no-offer implication & 5 & & $13.2 \%$ & \\
\hline & Call-taker proceeds & 6 & & $15.8 \%$ & \\
\hline & Other & 2 & & $5.3 \%$ & \\
\hline \multirow{3}{*}{ Rejection } & After applicant accepts no-offer implication & 1 & \multirow{3}{*}{7} & $2.6 \%$ & \multirow{3}{*}{$18.4 \%$} \\
\hline & After applicant resists no-offer implication & 4 & & $10.5 \%$ & \\
\hline & Other & 2 & & $5.3 \%$ & \\
\hline & Total & \multicolumn{2}{|c|}{38} & \multicolumn{2}{|c|}{$100 \%$} \\
\hline
\end{tabular}

Table 3: Frequency of rejections and non-rejections in informing sequences

These data show that when representatives use solicitations to determine an applicant's eligibility, they are much more likely to produce a rejection. The relationship between method (informing or soliciting) and the occurrence of a rejection is highly significant (Fisher's exact test, $p<.0001)$.

These findings suggest that university representatives should use informings rather than solicitations when determining applicant eligibility. This way, rejections are systematically and structurally disfavoured. Informing the applicant of the grade requirements for a course allows all participants to bypass the giving and receiving of an overt rejection.

\subsection{Application of findings}

This analysis of the sequential organization of rejections was part of a larger project on clearing and adjustment. The aim of this project was to develop recommendations that would demystify 
the process and make it less unpleasant for all parties. To this end, we identified recurrent practices such as the ones presented above, developed recommendations for both applicants and university representatives, and delivered our recommendations during admissions season in the year following data collection. For applicants, we described our research in popular pieces for online outlets like the Guardian and The Conversation, and we also discussed our findings in videos that appeared on the website of university that gave us the telephone data. For university representatives, we delivered our findings through a training video, which call handlers watched in preparation for fielding hundreds of clearing calls.

Our specific recommendation to inform rather than solicit particularly resonated with the call centre staff. After clearing and adjustment finished, we solicited feedback about the training video. We received six responses, and all those who commented reported the usefulness of our recommendation. Here are some examples of their feedback:

I found the first idea particularly useful. It felt much more positive for the caller to realise that their grades didn't match than for me to try and phrase a negative reply in a positive way! I think this also shortened some calls as once the caller realised that they'd not got the grades they ended the call (Call Handler 1).

The main thing I found useful from the [training] video shared for the Contact Centre was Tip 1 - to list grade requirements and reduce the need to give a negative response. I found this really reduced confusion on the phone, prevented callers getting their hopes up unnecessarily and shortened the conversation so that callers could ring another university quickly if they wished to. Part of my role is to attend Higher Education Fairs where we are frequently asked for details of courses and I will be using the advice in this context as well (Call Handler 2).

The one point that really made a difference was point 1 (inform of requirements first rather than soliciting grades achieved) which I used a lot as most of the calls this year were from clearing applicants with lower than required grades (Call Handler 3). 
The initial advice about giving students the requirements made it easier for students to make up their own mind. This removed the need for me to let them down and made the conversation easier (Call Handler 4).

These positive evaluations lend some validity to our analysis of rejections. The responses not only highlight our main finding - the avoidance of rejections vis-à-vis informings—but also indicate how this practice may serve other institutional goals. By way of avoiding rejections, representatives were also able to shorten calls (Call Handlers 1,2) and reduce confusion (Call Handler 2). The institutional actors are thus served by using informings insofar as the calls are quick and the representatives are relieved of the burden of giving rejections. Respondents also noted that this practice served the applicants, who could "make up their own mind" (Call Handler 4) and "ring another university quickly if they wished to" (Call Handler 2).

So, while it could be argued that the burden or agency of an informing sequence makes it harder on applicants, one could equally argue that it reduces the burden and agency on both parties to have to handle the misalignment/accountability that ensues following inquiries. One might also argue that shorter calls serve the collectivity of student applicants, because shorter calls increases the overall volume that can be dealt with in a shorter time. Given that competition may increase as the 'clearing' day progresses, applicants are likely to have their individual inquiries dealt with more rapidly, enabling them to make subsequent calls more rapidly - and ultimately secure a place elsewhere.

\subsection{Discussion}

This paper has examined how call-takers at a contact centre manage to reject potential students from university programmes, in ways that do and do not involve having to deliver bad news explicitly. In the recorded telephone calls that we studied, student callers were often ineligible for a university place, meaning that call-takers had to handle both rejection and ineligibility in these short, yet life-shaping conversations.

Our analysis of clearing and adjustment calls shows that call-takers chiefly rely on two methods for determining an applicant's eligibility for a given course. On the one hand, university representatives may solicit the applicant's grades, in which case they are then in a position to render a decision about the application. And on the other hand, the representative may inform the 
applicant of the grades required to be admitted to a particular course, in which case it is the applicant who then guides the application process at that moment. The sequential trajectories of solicitation and informing sequences were shown to be different in another respect as well. Solicitation sequences structurally provide for the occurrence of a rejection, whereas informing sequences provide possibilities for the avoidance of an overt rejection.

The examination of a high-rejection setting contributes to work on preference organization in institutional encounters. In contrast to institutional settings where clients are commonly entitled to service (Sikveland et al., 2016) and where institutional incumbents work to develop requests in 'grantable' directions (Lee, 2011), the desires of callers in clearing and adjustment calls are likely to go unsatisfied. Call handlers were tasked with rationing offers and routinely oriented to rejections as dispreferred actions by delaying, mitigating, and accounting for their rejections of the callers' applications. The applicants, however, showed fewer systematic orientations to rejections as dispreferred actions. This asymmetry is likely related not only to the high probability of rejection in these calls, but also to the fact that a rejection in one call does not completely foreclose the applicant's prospects. During the clearing and adjustment process, applicants can inquire into several courses at several universities. Receiving a rejection for one course at one university is only that. Applicants may not treat rejections as dispreferred because other possibilities still remain.

Our account of how participants determine eligibility also indicates how the distribution of knowledge (Heritage, 2012) may intersect with entitlement and contingency in interaction (Curl \& Drew, 2008). Ascertaining an applicant's eligibility is contingent upon their A-level grades, which are known by the caller, and the course's grade requirements, which are known by the call-taker. So there is asymmetric access to the information needed for the progressive development of the call. The methods by which this matter is handled (see Section 3.1) can reveal participants' orientations to a range of situational contingencies. The call-takers cannot know, of course, what grades an applicant has received or whether they've already been given a conditional offer (see Appendix). And conversely, the callers cannot know for certain if a course has just reached capacity or if it's open only to international students. The activity of determining eligibility thus involves an assembly of practices connected to the organization of preference, knowledge, and requesting. And though our account is restricted to the call centre data analysed 
here, we suggest that its implications for studying eligibility is something that researchers in conversation analysis might examine more closely.

\section{Appendix}

In undergraduate admissions in the UK, a student typically applies to a particular course of study at a particular university in the fall/winter of their final year of school. The university then decides whether to give them an offer. If no offer is given, then the student may still find a place on some other course through clearing. Alternatively, if an offer is made, it may be unconditional or conditional. An unconditional offer means the student has been accepted and can enroll if they wish to do so. A conditional offer stipulates that they will only be admitted if they receive particular grades on particular A-level exams.

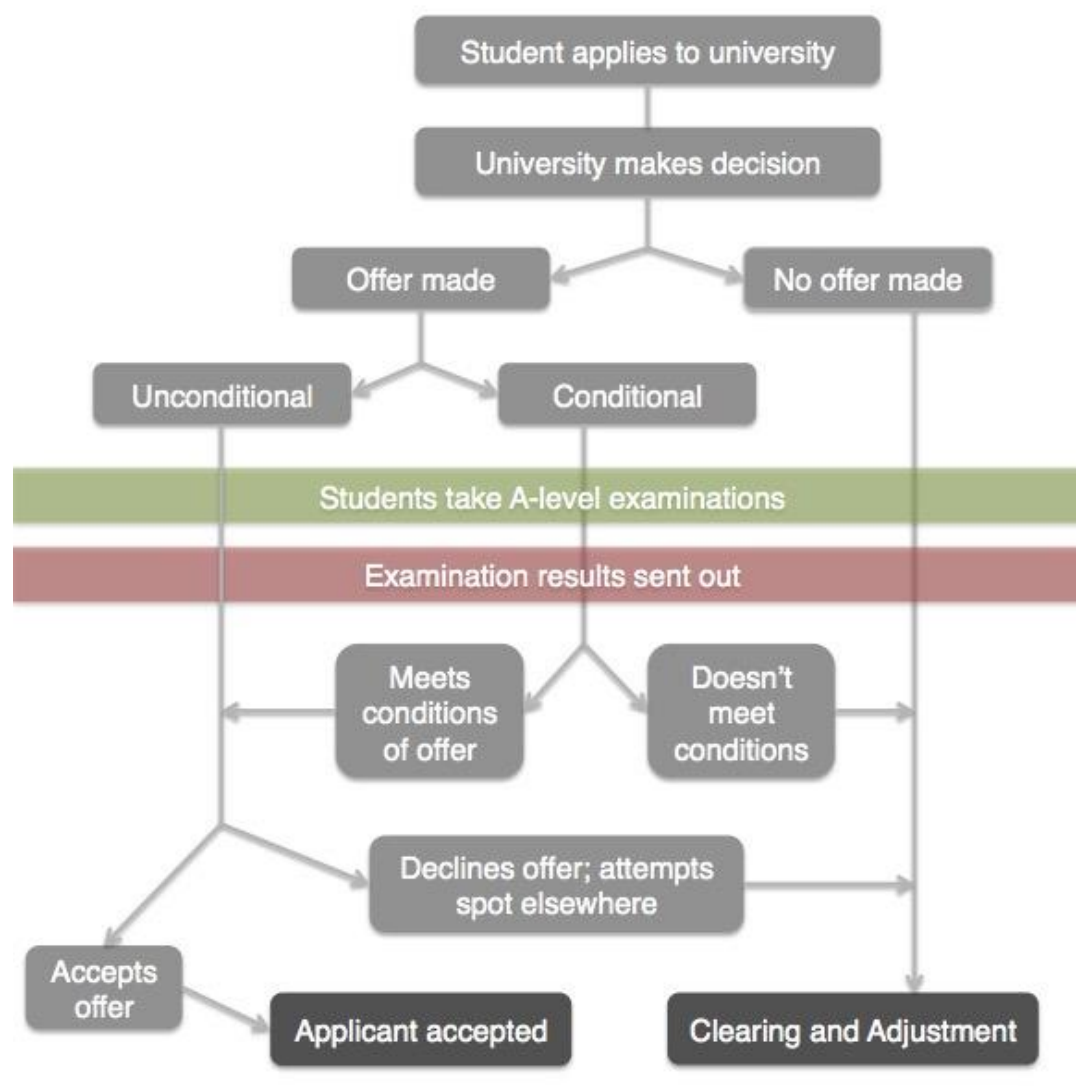

Figure 1: Typical procedure for undergraduate admissions at UK universities 
After this initial process of applying and receiving offers, students sit their A-level exams in the spring, and results are released late summer. For students holding conditional offers, their Alevel results indicate whether they've satisfied, exceeded, or failed to meet the conditions of their offer. If successful in meeting them, they may enroll in that course at that university. But if unsuccessful, then their only option is to go through clearing.

After results are released, clearing and adjustment begins. Those applying through clearing have either not received an offer or have not met the conditions of their offer. These applicants call universities to see if they 'clear' the threshhold to be admitted onto another course - basically, to see what they can get with the grades they've received. Those applying through adjustment have generally received better-than-required A-level grades and are calling to potentially 'adjust' or 'trade-up' to a more desirable course and/or university.

\section{Acknowledgements}

This research was previously presented at the $5^{\text {th }}$ International Conference for Conversation Analysis, Loughborough, UK. The analysis has benefitted from the helpful suggestions from three anonymous reviewers, as well as feedback and references provided by Ruth Parry. We also thank Rein Sikveland and Sophie Parslow for project support.

\section{References}

Atkinson, J. M., \& Drew, P. (1979). Order in court: The organisation of verbal interaction in judicial settings. London: Macmillan.

Beach, W. A. (1993). Transitional regularities for casual 'okay' usages. Journal of Pragmatics, $19,325-352$.

Brown, P., \& Levinson, S. C. (1987). Politeness: Some universals in language usage. Cambridge: Cambridge University Press.

Clayman, S. E. (2002). Sequence and solidarity. In E. J. Lawler \& S. R. Thye (Eds.), Advances in group processes: Croup cohesion, trust, and solidarity (pp. 229-253). Oxford: Elsevier Science.

Curl, T. S., \& Drew, P. (2008). Contingency and action: A comparison of two forms of requesting. Research on Language and Social Interaction, 41(2), 129-153.

Drew, P., \& Heritage, J. (Eds.). (1992). Talk at work: Interaction in institutional settings. 
Cambridge: Cambridge University Press.

Fox, B. (2015). On the notion of pre-request. Discourse Studies, 17(1), 41-63.

Gill, V. T., \& Maynard, D. W. (1995). On 'labeling' in actual interaction: Delivering and receiving diagnoses of developmental disabilities. Social Problems, 42(1), 11-37.

Global Education Monitoring Report. (2017). Six ways to ensure higher education leaves no one behind (Policy Paper 30). Paris: UNESCO.

Greatbatch, D. (1992). On the management of disagreement between news interviewees. In P. Drew \& J. Heritage (Eds.), Talk at work: Interaction in institutional settings (pp. 268301). Cambridge: Cambridge University Press.

Hepburn, A., \& Bolden, G. B. (2017). Transcribing for social research. Sage.

Heritage, J. (1984). Garfinkel and ethnomethodology. Cambridge: Polity Press.

Heritage, J. (2015). Well-prefaced turns in English conversation: A conversation analytic perspective. Journal of Pragmatics, 88, 88-104.

Heritage, J., \& Sorjonen, M.-L. (1994). Constituting and maintaining activities across sequences: And-prefacing as a feature of question design. Language in Society, 23(1), 1-29.

Hoey, E. M. (2015). Lapses: How people arrive at, and deal with, discontinuities in talk. Research on Language and Social Interaction, 48(4), 430-453

Hoey, E. M. (in press). How speakers continue with talk after a lapse in conversation. Special issue of Research on Language and Social Interaction.

Hoey, E. M., \& Kendrick, K. H. (2018). Conversation Analysis. Research Methods in Psycholinguistics and the Neurobiology of Language: A Practical Guide (pp. 151-173). London: Wiley-Blackwell.

Hofstetter, E., \& Stokoe, E. (2015). Offers of assistance in politician-constituent interaction. Discourse Studies, 17(6), 724-751.

Lee, S. H. (2011). Managing nongranting of customers' requests in commercial service encounters. Research on Language and Social Interaction, 44(2), 109-134.

Lynch, M. (1985). Art and artifact in laboratory science. A study of shop work and shop talk in a research laboratory. London: Routledge and Kegan Paul.

Maynard, D. W. (1997). The news delivery sequence: Bad news and good news in conversational interaction. Research on Language and Social Interaction, 30(2), 93-130.

Maynard, D. W. (2004). On predicating a diagnosis as an attribute of a person. Discourse 
Studies, 6(1), 53-76.

Maynard, D. W. (2013). Defensive mechanisms: I-mean prefaced utterances in complaint and other conversational sequences. In M. Hayashi, G. Raymond, \& J. Sidnell (Eds.), Conversational Repair and Human Understanding (pp. 198-233). Cambridge, U.K.: Cambridge University Press.

Pillet-Shore, D. (2017). Preference organization. In J. Nussbaum (Ed.), Oxford Research Encyclopedia of Communication. New York: Oxford University Press.

Pomerantz, A. M. (1984). Agreeing and disagreeing with assessments: Some features of preferred/dispreferred turn shapes. In J. M. Atkinson \& J. Heritage (Eds.), Structures of social action: Studies in conversation analysis (pp. 57-101). Cambridge: Cambridge University Press.

Pomerantz, A. M. (1986). Extreme case formulations: A way of legitimizing claims. Human studies, 9(2-3), 219-229.

Rossi, G. (2014). When do people not use language to make requests. In P. Drew \& E. CouperKuhlen (Eds.), Requesting in social interaction (pp. 303-334). Amsterdam: John Benjamins Publishing.

Sacks, H. (1987). On the preferences for agreement and contiguity in sequences in conversation. In G. Button \& J. R. E. Lee (Eds.), Talk and social organisation (pp. 54-69). Clevedon, UK: Multilingual Matters.

Sacks, H. (1992). Lectures on conversation. Oxford: Blackwell.

Schegloff, E. A. (2007). Sequence organization in interaction: A primer in conversation analysis. Cambridge: Cambridge University Press.

Sacks, H., \& Schegloff, E. A. (1973). Opening up closings. Semiotica, 8(4), 289-327.

Sidnell, J. \& Stivers, T. (Eds). (2013). The handbook of conversation analysis. Oxford: Wiley-Blackwell.

Sikveland, R., Stokoe, E., \& Symonds, J. (2016). Patient burden during appointment-making telephone calls to GP practices. Patient education and counseling, 99(8), 1310-1318.

Stivers, T. (2004). 'No no no' and other types of multiple sayings in social interaction. Human Communication Research, 30(2), 260-293.

Tracy, K. (1997). Interactional trouble in emergency service requests: A problem of frames. Research on Language and Social interaction, 30(4), 315-343. 
Varcasia, C. (2007). English, German, and Italian responses in telephone service encounters. In H. Bowles \& P. Seedhouse (Eds.), Conversation analysis and language for specific purposes (pp. 217-244). Bern, Switzerland: Peter Lang.

Whalen, J., \& Zimmerman, D. H. (1998). Observations on the display and management of emotion in naturally occurring activities: The case of "hysteria" in calls to 9-1-1. Social Psychology Quarterly, 61, 141-159.

Whalen, M. R., \& Zimmerman, D. H. (1990). Describing trouble: Practical epistemology in citizen calls to the police. Language in Society, 19, 465-492.

Wilkinson, S. \& Kitzinger, C. (2006). Surprise as an interactional achievement: Reaction tokens in conversation. Social psychology quarterly, 69(2), 150-182.

Wootton, A. J. (1981). The management of grantings and rejections by parents in request sequences. Semiotica, 37(1-2), 59-90. 